\title{
HEGEMONIA E QUESTÃO FEMININA EM ANTONIO GRAMSCI
}

\begin{abstract}
ANA MARIA SAID ${ }^{1}$
RESUMO: No contexto de crise de autoridade, como definia Antonio Gramsci, em que há um avanço da extrema direita em muitos e importantes países do mundo, se instala a questão das minorias, dos preconceitos e das discriminações, da violência sobre elas, como manifestação do comportamento retrógrado e conservador da sociedade individualista e de massas. Para Gramsci, a luta política pela hegemonia no capitalismo contemporâneo é empreendida na sociedade civil, como base para as lutas contra a opressão. É no terreno político-econômico que a superação da condição de subalternidade das minorias se coloca. E a questão feminina está incluída nesse contexto. A reforma intelectual e moral seria a estratégia para que essa superação fosse possível. As mudanças na vida material contemporâneas impulsionam as conquistas femininas e sua afirmação como sujeito histórico, possibilitando uma inserção social e econômica. Mas, como todas as minorias, suas lutas específicas devem estar embasadas pela organização de classes. Gramsci nunca se ocupou especificamente sobre a "questão feminina". É provável que se possa entender o papel da mulher na sociedade, para Gramsci, ao pensá-la a partir do conceito de "hegemonia" e sua definição de subalternidade e de sua superação. É a análise que pretendemos desenvolver nesse texto.
\end{abstract}

PALAVRAS-CHAVE: Hegemonia, política, mulher, subalternidade, emancipação

\begin{abstract}
In the context of authority crisis, as Antonio Gramsci defined, there is an advance of the far right in many important countries worldwide. The issue of minorities is installed, prejudice, discrimination and violence as a manifestation of this old and conservative behavior of individualist society and masses. For Gramsci, the political struggle for hegemony in the contemporary capitalism is undertaken in the civil society as the basis for struggles against oppression. It is in the politic-economical ground that the overcoming of the minorities' subordinate condition arises. The feminine issue is included in this context. The intellectual and moral reform would be the strategy to enable this overcoming. Changes in the contemporary material life boost the feminine achievements and their affirmation as historical subject, enabling a social and economic insertion. But, as all minorities, their specific struggles must be based on the organization of classes. Gramsci never specifically occupied himself with the "feminine issue". Yet it is probable that for Gramsci the role of woman in society could be understood while thinking about it from the concept of "hegemony" and its definition of subordination and overcoming. This is the analysis we intend to develop in this text.
\end{abstract}

KEYWORDS: Hegemony, politics, woman, subordination, emancipation

\footnotetext{
${ }^{1}$ Professora Titular da Universidade Federal de Uberlândia (UFU). Doutora em Educação pela Universidade Estadual de Campinas (UNICAMP). E-mail: anasaid18@hotmail.com.
} 
Vivemos na atualidade um momento agudíssimo de crise, em que os totalitarismos afloram e a questão da hegemonia está colocada como crise de autoridade, como crise hegemônica, como definia Antonio Gramsci. Nesse contexto em que há um avanço da extrema direita em muitos e importantes países do mundo, se instala a questão das minorias, dos preconceitos e das discriminações, da violência sobre elas, como manifestação do comportamento retrógrado e conservador da sociedade individualista e de massas.

Para Gramsci, a luta política pela hegemonia no capitalismo contemporâneo é empreendida na sociedade civil, como base para as lutas contra a opressão. É no terreno político-econômico que a superação da condição de subalternidade das minorias se coloca. E a questão feminina está incluída nesse contexto. Existem possibilidades várias de abordar a questão da mulher em Antonio Gramsci. Em suas relações familiares e no diálogo epistolar do cárcere com elas, no seu olhar desafiador, segundo acusa em algumas cartas, sobre a subalternidade de sua esposa Giulia Schucht, e no posicionamento nas relações com as mulheres que lhe eram importantes, principalmente no diálogo, quase debate, com Tatiana Schucht, sua cunhada e interlocutora no período carcerário através de cartas. $\mathrm{O}$ apoio de Tania é incondicional ao prisioneiro Gramsci, revelando nessa correspondência uma profunda visão intelectual da sociedade em que vivia, mas, principalmente, possibilitando comunicação com seus companheiros fora da prisão, como por exemplo, Pierro Sraffa e, principalmente, Palmiro Togliatti através deste, que o substitui na direção do Partido, o que foi fundamental para continuar a alimentar a sua compreensão agudíssima do que ocorria no mundo exterior ao cárcere e persistir participando da luta política contra o fascismo e pela construção do socialismo, insistindo em elaborar uma estratégia possível para os trabalhadores.

Gramsci nunca se ocupou especificamente sobre a “questão feminina”. É provável que se possa entender o papel da mulher na sociedade, para Gramsci, ao pensa-la a partir do conceito de "hegemonia". É o que pretendemos pensar nesse texto.

É em Tania que ele encontra um interlocutor e um cúmplice para continuar em contato com o mundo, mesmo no cárcere, embora seja contraditória sua relação com a Tania-mulher, acusando-a de possuir características tipicamente "femininas", que impedem que ela trate objetivamente dos problemas, acusando-a, também, de agir impetuosamente na tentativa de solucioná-los. Será, porém, em seu diálogo truncado com Giulia, sua esposa, que encontramos possibilidades, em sua estratégia política, para o subalterno, nesse caso a mulher, como tantas vezes se refere à sua companheira, superar a subalternidade. A reforma intelectual e moral seria a estratégia para que essa superação fosse possível. 
Para Gramsci, não é possível uma reforma intelectual e moral sem que haja uma mudança na posição social e na vida material:

(...) por isso, afirma, uma reforma intelectual e moral não pode deixar de estar ligada a um programa de reforma econômica, e mais, o programa de reforma econômica é exatamente o modo concreto através do qual se apresenta toda reforma intelectual e moral (GRAMSCI, 1975, p. 1561)

As mudanças na vida material contemporâneas impulsionam as conquistas femininas e sua afirmação como sujeito histórico, possibilitando uma inserção social e econômica e, principalmente, uma participação mais efetiva nas lutas sociais. Mas, como todas as minorias, suas lutas específicas devem estar embasadas pela organização de classes.

Não existe um movimento maquinal que transforme a história, já que para isso são necessários forças e sujeitos que se definam no terreno das superestruturas, com seus interesses econômicos e culturas, com orientações políticas e ideológicas.

São as crises orgânicas que possibilitam o crescimento civil em uma dada formação social, pois possibilitam trabalhar o contraditório que esta traz em seu interior com a potência criativa dos sujeitos entre os vários grupos que se organizam e orientam para os confrontos sociais na sociedade capitalista. Aqui se encontra a importância da luta pela democracia que seria o lugar onde novos sujeitos definiriam seu papel e as próprias estratégias, constituindo-se para viverem livres em toda a sua plenitude, no coletivo social. E a mulher, definida por Gramsci como parte do grupo de subalternos na sociedade capitalista, como podemos aferir de suas cartas às mulheres com as quais se relacionava, era parte desse processo de transformação cultural.

Uma prática cultural que conseguisse, ao mesmo tempo, ser parte da vida e possibilidade de crescimento social seria o nó central do processo de formação humana, projeto de uma sociedade justa e igualitária. Segundo Adolfo Sanchez Vasquez:

O indivíduo - como sujeito dotado de consciência e vontade - deve superar a condição de suporte ou efeito passivo de uma estrutura social para integrar-se livre e conscientemente na comunidade e desenvolver, mais do que nunca, sua responsabilidade pessoal e, com isso, a sua própria natureza moral. (VASQUEZ, 1990,p. 63)

Gramsci escreve em uma carta de 1932, a partir de um conto, uma comparação da atitude que deveria servir de guia para Giulia com a novela Um uomo in um fosso, de Lucien Jean, comparando a situação dela como subalterna à de um homem que havia bebido muito, estava um pouco alucinado com a visão de belas mulheres, e que caiu em um fosso, do qual não conseguia sair. As moitas se puseram sobre ele, as lesmas o riscaram de prata, um sapo se pousou em seu coração para sentir suas batidas, para saber se ainda estava vivo, e ele não se 
mexia. Vários personagens passaram por ele, somente o criticaram, mas não o ajudaram a sair do fosso, até que ele próprio percebeu que podia sair. Escreve: “Assim, o homem continuava no fosso, até que olhou em volta, viu exatamente onde havia caído, se desvencilhou, alçou-se, fez força com os braços e as pernas, ficou em pé, e saiu do fosso com suas próprias forças." (GRAMSCI, 2013, pág. 421) E assim incita Giulia a superar-se: "Ocorre queimar todo o passado, e reconstruir toda uma vida nova: não é necessário deixar-se esmagar pela vida vivida até agora, ou ao menos é preciso conservar somente aquilo que foi construtivo e belo. É necessário sair do fosso e repelir o sapo do coração". (idem)

Em outra carta de 28 de novembro de 1932, ainda direcionada à sua mulher, é ainda mais enfático sobre a questão da feminilidade. Citamos:

\begin{abstract}
...meu interesse foi suscitado pelo fato de que seu argumento é ingênua e candidamente "feminino". A verdadeira quintessência da feminilidade. Porque ver no espelho só um instrumento de narcisismo é próprio das mulheres. Eu sempre tive um espelho; caso contrário, como poderia me barbear? Suas observações estão erradas de cabo a rabo e indicam um modo de pensar atrasado, anacrônico e... terrivelmente perigoso. Com seu estado de ânimo, negativo e puramente reativo a certas degenerações psicológicas, o operário arrebenta a máquina, o empregado remedeia suas práticas, etc... (GRAMSCI, 2013, p.642)
\end{abstract}

Entretanto, mesmo nas cartas, com a dificuldade da distância e da solidão, ele buscava dividir a responsabilidade da educação dos filhos, e da vida da mulher e, assim de forma dura, ao acusá-la de estar na posição de "subalterno", consegue definir o que conceitua como tal. Escreve para Giulia em 8 de Agosto de 1933:

Em geral, parece-me que tu te pões (e não somente neste argumento) na posição do subalterno e não do dirigente, isto é, de quem não está em nível de criticar historicamente as ideologias, dominando-as, explicando-as e justificando-as como uma necessidade histórica do passado, mas de quem, posto em contato com um determinado mundo de sentimentos, sente-se por ele seduzido ou repelido, permanecendo, no entanto, sempre na esfera do sentimento e da paixão imediata. (GRAMSCI, 2013, p. 736)

Nesse sentido, o termo subalterno tem uma significação especificamente cultural, como aquele que não possui capacidade de historicidade, visão crítica, capacidade hegemônica, e que se mantém no domínio do sentimento e das paixões.

Escreve Guido Liguori que:

Mostra-se claro como os limites que Gramsci vê na companheira são reconduzíveis em grande parte a uma certa concepção das mulheres, sobretudo masculina, que hoje diremos machista ou patriarcal, à qual Gramsci não parece subtrair-se. Entretanto, o uso do termo presente na carta pode ser certamente estendido a outros sujeitos, até mesmo aos que estão fora desse olhar "machista". (LIGUORI, 2014, pág.20)

Seu posicionamento sobre a visão "feminina" de Giulia é perceptível nesse trecho de carta e de diálogo truncado sobre a educação dos filhos, por alguém impotente para interferir 
na formação deles. Mas refletiria sua posição sobre a questão feminina como tantas análises sugerem?

Muito se escreveu sobre o posicionamento de Gramsci frente às suas relações com as mulheres de sua família, principalmente o que fica registrado nas Cartas do cárcere. Porém, para além de sua condição de encarcerado, impossibilitado de conviver e educar seus filhos, que se encontravam, além disso, distantes geográfica e emocionalmente, de relacionar-se afetiva e cotidianamente com a esposa, com a mãe, irmãs, etc..., havia sua dificílima condição de saúde na prisão, quase inimaginável. Entretanto, seria retalhar ainda mais seu pensamento, já tão difícil por sua condição para escrever na prisão, atermo-nos somente a esse aspecto de suas reflexões para pensarmos a questão feminina em sua obra.

Fundamentalmente o que nos instiga em nossa análise é sua definição da mulher, por um lado como subalterna, como podemos inferir de suas cartas familiares, por outro, na forma como se preocupa com a ascensão civil e política dos subalternos, nos Cadernos do cárcere e, inclusive, como incita sua esposa a superar seus limites.

Lea Durante, em artigo na Revista Critica Marxista de 2008, questiona exatamente o uso da obra gramsciana para pensar a possibilidade da mulher superar a opressão, incluindo-a na condição de "subalterno". Escreve:

\begin{abstract}
Para além de adequado ou menos, dos usos mais recentes e controversos de certos esboços de trabalho gramscianos, parece-me interessante notar como para Gramsci a definição de grupo subalterno implique sempre a possiblidade de uma afirmação histórica, de uma participação na luta pela hegemonia, mesmo que em tempos e modos não sempre previsíveis, pelos grupos subalternos, precisamente. Ser um grupo subalterno, na história dos estados e da sociedade é uma fase, ou uma progressão certamente não linear e unidirecional, mas contraditória e não descontada nos êxitos - de fases diversas tendentes à superação das condições de "desagregação". (DURANTE, 2008, p.43)
\end{abstract}

Mas, contrapõe ela, Gramsci não inclui as mulheres nos grupos que sofreram historicamente opressão, e assim, para ele, elas "não podem afirmar-se como alteridade, como diferença que não visa à inclusão dentro da ordem existente, mas pretendem modificá-la. Isso para Gramsci simplesmente não existe",.(idem)

É nos Cadernos, porem, precisamente em seu texto de 1934, "Americanismo e fordismo", no Caderno 22, que Gramsci demonstra, mais que em outros momentos de sua obra, a preocupação com a questão feminina, em sua análise antropológica do fenômeno americano, como "o maior esforço coletivo verificado até agora para criar com rapidez inaudita e com uma consciência do objetivo final nunca vista na história, um tipo novo de trabalhador e de homem". Assim, segundo Gramsci, a americanização requer certo ambiente, uma dada estrutura social e 
certo tipo de Estado, que seria o liberal. Para isso, é preciso criar um novo tipo humano, conforme ao tipo de trabalho e do processo produtivo.

A contradição que o processo de americanização efetiva cria, ao mesmo tempo, com a opressão, a possibilidade da organização da luta dos subalternos para sua emancipação, da luta hegemônica. Aí está o cerne da questão feminina, já que nesse mesmo texto sobre o americanismo, Gramsci dedica grande atenção à questão sexual e à questão feminina, acentuando que a questão ético-civil mais importante ligada à questão sexual é aquela da formação de uma nova personalidade feminina. Um avanço em seu posicionamento sobre as mulheres nos anos de 1920. Mas, este seria um dos seus últimos escritos. Em 1934, com a saúde pior a cada dia, e sem tempo e amadurecimento necessários para continuar a desenvolver suas reflexões, apenas nos aponta a importância da reforma intelectual e moral na formação humana e na transformação histórica e social.

Escreve no Caderno 22:

A questão ético-civil mais importante ligada à questão sexual é aquela da formação de uma nova personalidade feminina: até que a mulher não tenha alcançado uma real independência diante do homem, mas também um novo modo de conceber a si mesma e o seu papel nas relações sexuais, a questão sexual permanecerá rica de características morbosas e será necessário sermos cautos em toda inovação legislativa. (GRAMSCI, 1975, ps. 2149-2150)

Queremos enfatizar que ele trata da questão ético-civil no âmbito dos costumes, e não no da política. Se existe um dado determinismo de Gramsci em sua análise antropológica do fenômeno americano, não é por isso menos fecundo na análise do fenômeno americano como decisivo de um modo de viver e de ser humanos, criados por este. E a questão sexual e a subalternidade feminina como base do núcleo familiar patriarcal seriam a possibilidade de construção de uma renovada hegemonia burguesa, com um acirramento da exploração, enquanto cediam a pressões que não comprometessem, mas ao contrário, permitissem um controle maior da vida privada de cada trabalhador, como as vilas operárias e seus administradores, os seguros saúde, o tratamento do alcoolismo, e coisas afins.

Com o fordismo, a racionalização é um elemento de transformação objetiva da organização do trabalho e das relações sociais, do modo de viver e de novos costumes, criando uma realidade da qual não se pode prescindir para analisar as mudanças por ele engendradas. O fordismo, segundo Gramsci, controlou a modernização, numa perspectiva históricouniversal, mas não colocou a questão fundamental da hegemonia. Acontece como revolução passiva, imposta do alto, com mudanças nos novos métodos de trabalho, com concessões aos trabalhadores, mas com opressão ainda maior, e não possibilita nenhum desenvolvimento da 
"superestrutura", já que mantém a dominação dos subalternos. Mas o "americanismo" promove mudanças a partir da "formação" de novos hábitos, costumes e valores para a grande massa de trabalhadores, e consegue movê-las para adaptar-se a um novo "modo de viver", sendo este base para a manutenção do poder da classe dominante. $\mathrm{O}$ controle exercido pelo fordismo na vida dos trabalhadores, em seu modo de ser, é ainda mais efetivo no fascismo, com um controle ideológico ainda mais rígido, com um grande poder de convencimento, porque baseado nas paixões e não em escolhas políticas racionais. E o domínio ainda maior sobre as mulheres é crucial para esse processo.

Segundo Gramsci, "não se pode desenvolver o novo tipo de homem, requerido pela racionalização da produção e do trabalho, enquanto o instinto sexual não for regulado em conformidade, não for também ele racionalizado." (GRAMSCI, 1975, p. 2150) E completa mais à frente que "já que os novos métodos de trabalho são indissolúveis de um determinado modo de viver, de pensar e de sentir a vida: não se pode obter sucessos num campo sem obter resultados tangíveis no outro." (GRAMSCI, 1975, p. 2164)

O sistema patriarcal, que o capitalismo reforça desde seus primórdios, se reforça com o fordismo, com o puritanismo, ideologia fundamental para a retomada da hegemonia burguesa nos EUA da década de 1920 e 1930, com os novos métodos de trabalho e novo modo de vida correlacionado a eles.

É assim que o fordismo reforça o puritanismo e o proibicionismo, ligados diretamente à racionalização do trabalho, usados com brutal cinismo dos industriais de tipo Ford para atingir o objetivo da sociedade americana, que seria desenvolver no trabalhador atitudes maquinais e automáticas, "reduzindo as operações produtivas ao seu único aspecto físico maquinal". (GRAMSCI, 1975, p. 2165) Eles não se preocupavam com a "humanidade" e com a "espiritualidade" do trabalhador, "que é imediatamente arruinada." (idem) Interessavam-se na verdade, em manter a continuidade física dele, sua eficiência muscular nervosa para o mundo da produção, o modo de vida "americano", o recrudescimento do patriarcalismo como fundamento da renovada hegemonia burguesa.

É nesse sentido que o proibicionismo do álcool torna-se ideologia estatal, coloca o controle do álcool e da vida sexual como questão central para a formação desse novo tipo de homem exigido pelos novos métodos de trabalho, já que este seria o inimigo mais perigoso das energias nervosas, juntamente com o abuso e irregularidade das funções sexuais, posto que o trabalho obsessionante provoca depravação alcóolica e sexual. E a questão feminina e de 
liberdade de gênero estará ligada à questão sexual exigida pela nova sociedade. Os excessos eram definidos como prejudicial à vida produtiva.

Tornemos a questão feminina dentro desse contexto. A passividade feminina é uma necessidade do americanismo, em que a mulher tem uma função ativa na vida privada, no lar, cuidando dos filhos, e uma função passiva na vida pública e produtiva do país, o que possibilita que a racionalização da produção e a criação do "gorila domesticado", projetados por Taylor, sejam possíveis. Essa passividade acaba por tornar-se um problema, já que contribui para formar, nos EUA, uma massa passiva que não existia anteriormente em sua composição social. A partir do americanismo se constitui uma nova sociedade de massas.

Então, não é de se estranhar que Gramsci coloque a questão feminina como questão ético-civil, dentro do quadro de mudanças dos costumes. Mas não sei se podemos afirmar que não haja uma intenção política em Gramsci, com relação às mulheres, como tantas análises sobre o tema sugerem. Não seria essa transformação ético-civil como aponta, fundamental para a contemporaneidade, essa formação de uma nova personalidade feminina, para além de uma nova forma de conceber a si mesma nas relações, a possibilidade da inclusão na luta política por uma outra hegemonia, um novo modo de viver e de ser humanos?

A obra de Gramsci expressa a condição de subalternidade da mulher e, ao mesmo tempo, permite que se pense sobre a capacidade de ir conformando a própria personalidade, ao participar ativamente na transformação do mundo. No Caderno 10 afirma: "Por isso se pode dizer que cada um muda a si mesmo, se modifica, na medida em que muda e modifica todo o conjunto das relações de que ele é o centro de ligação". E um pouco mais adiante pondera: "Se a própria individualidade é o conjunto dessas relações, construir-se como personalidade significa adquirir consciência de tais relações, modificar a própria personalidade significa modificar o conjunto dessas relações”. (GRAMSCI, 1975, pág. 1345)

É, então, na luta pela transformação social que a mulher pode ir, ao mesmo tempo, forjando uma nova personalidade, em que participe ativamente como sujeito histórico, o que implica nova sociedade e forma de produzir a vida humana. É necessária, então, compreensão crítica de si, o que somente é possível com uma luta de hegemonias políticas contrastantes, primeiro no campo da ética, afirma Gramsci, depois no da política. Não incluirmos a questão política com relação à mulher, nesse sentido, seria dividir a obra gramsciana, ao pensarmos especificamente a questão feminina, mesmo que Gramsci não tenha apontado a fundamental importância da superação da sociedade patriarcal, o mais formidável aliado do modelo capitalista, o faz analisando o papel feminino na manutenção da hegemonia dos proprietários 
no americanismo. Para ele, transformar o mundo, as relações gerais, significa potencializar a si mesmo, desenvolver a si mesmo (GRAMSCI, 1975, p. 1338). E há uma intrincada trama na superação da hegemonia burguesa, com a superação do patriarcalismo e a condição de subalternidade, inclusive a das mulheres.

Pensamos, portanto, que a obra de Gramsci permite pensar a questão feminina na luta por uma nova cultura, com sua emancipação forjada na transformação das relações sociais, na construção de uma nova hegemonia, como superação da subalternidade e da dominação de classes. A libertação feminina liga-se umbilicalmente à libertação humana, à superação da dominação, uma implica a outra na construção do mundo humano sem opressões, acesso igualitário às riquezas econômicas e culturais, seres humanos livres e iguais nas diferenças, utopia maior do materialismo histórico.

\section{REFERÊNCIAS BIBLIOGRAFICAS}

DURANTE, L. - La "formazione" di uma nuova personalità femminile in Critica Marxista, Roma, Ed. Dedalo, marzo-giugno, 2008.

GRAMSCI, A. Quaderni del Carcere: A cura di Valentino Gueratana. 2. ed.,. Edizione Critica dell'Istituto Gramsci. Torino: Ed. Einaudi, 1975.v. 1, 2, 3 e 4.

Lettere dal Carcere. Organização de Antonio A. Santucci. Palermo: Ed. Sellerio,2013.

IZZO, F., Democrazia e cosmopolitismo in Antonio Gramsci, Roma: Carocci Ed., 2009.

LIGUORI, G., Partido e subalternos em Gramsci e hoje in SAID, A.M. (org), Pensar a sociedade contemporânea: a atualidade do pensamento de Marx e Gramsci, Uberlandia, EDUFU, 2014.

MANCINA, C., Teoria dell'identità e questione femminile, in Oltre Gramsci com Gramsci, Critica Marxista, 1987, n.2-3.

RIGHI, M.L., Gramsci a Mosca tra amori e politica (1922-1923), Roma, Revista Studi Storici n. $4,2011$.

VASQUEZ, A. S., Filosofia da práxis, Rio de Janeiro, Paz e Terra, 1990. 